\title{
Recurrent herpes simplex virus ocular infection: epidemiological and clinical features
}

\author{
M S WISHART, S DAROUGAR, AND N D VISWALINGAM \\ From the External Eye Diseases Clinic, Moorfields Eye Hospital, and the Subdepartment of Virology, Institute \\ of Ophthalmology, London
}

SUMMARY The epidemiological and clinical features of recurrent herpes simplex virus ocular infection (RHSV) were studied. Of 108 patients with primary herpes simplex virus ocular infection (PHSV) who were followed up for two to 15 years $35(32 \%)$ suffered one or more recurrent attacks. The recurrence rate was significantly higher in patients under 20 years of age, but there was no significant difference between recurrence rates in males and females. Of 35 patients with RHSV 17 $(49 \%)$ had one recurrent attack, $14(40 \%)$ had between two and five, and four $(11 \%)$ had between six and 15 attacks. The mean time interval between PHSV and the first four RHSV attacks was 10 months, and was shorter in subsequent attacks. The duration and severity of RHSV were reduced in successive recurrences. Patients with more severe conjunctivitis and lid lesions during PHSV ocular infection had a higher incidence of recurrent infection. The severity of the corneal signs in PHSV had no influence on the incidence of recurrent infection. Several clinical forms of RHSV were observed. Conjunctivitis associated with lid lesions was observed in $29(83 \%)$ patients. In six $(17 \%)$ patients the disease presented as an acute follicular conjunctivitis without characteristic lid or corneal lesions. Dendritic ulcer was found in three (9\%) patients, and in one of them it was associated with a disciform keratitis. A chronic blepharoconjunctivitis developed in eight $(23 \%)$ patients. The epidemiological and clinical features of RHSV were compared with those of PHSV.

In a previous report ${ }^{1}$ we presented the epidemiological and clinical features of primary herpes simplex virus (PHSV) ocular infection in patients attending an ophthalmic clinic in London. We found that primary ocular infections were commoner in the age group 15-20 years than in others and that in onethird of the patients it was associated with systemic disorder. The commonest clinical form observed was conjunctivitis with associated lid lesions. Follicular conjunctivitis without lid or corneal lesions, dendritic ulcer, and disciform keratitis were also found.

In this report we present epidemiological and clinical features of recurrent herpes simplex virus (RHSV) ocular infection in patients who were included in our study of PHSV ocular infection.'

\section{Patients and methods}

One hundred and eight patients with PHSV attending

Correspondence to Mrs M S Wishart, FRCS, Subdepartment of Virology, Institute of Ophthalmology, Judd Street, London WC1H 9QS the External Eye Diseases Clinic at Moorfields Eye Hospital were followed up for recurrent attacks for two to 15 years. The criteria for the diagnosis of PHSV and the epidemiological and clinical features are presented elsewhere.'

The methods of clinical examination and virus isolation in patients with RHSV were carried out as described previously. ${ }^{2-4}$ A diagnosis of RHSV ocular infection was based on the detection of herpetic lid vesicles and/or ulcer, corneal ulcer, or HSV isolation from the conjunctiva. Statistical analysis was carried out by $\chi^{2}$ tests.

\section{Results}

Age and sex. Of 108 patients with PHSV ocular infection $35(32 \%)$ developed one or more attacks of RHSV ocular infection. Their ages ranged from 18 months to 56 years, mean 18 years. The distribution of patients' ages in relation to PHSV and RHSV ocular infections is shown in Fig. 1. The prevalence of RHSV ocular infection in patients under 20 years of 


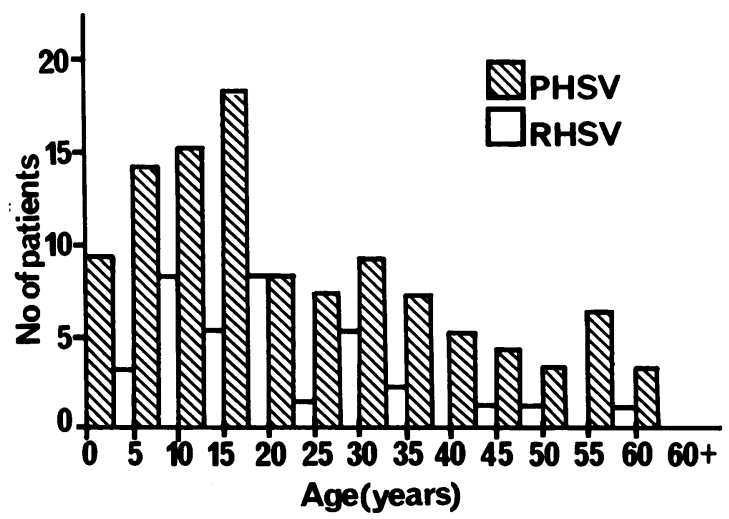

Fig. 1 Age distribution of 108 cases of PHSV and the 35 patients who developed RHSV ocular infections.

age was significantly higher than that observed in the older patients $(p<0 \cdot 03$, Table 1$)$. RHSV developed in 16 of $58(28 \%)$ male patients and in 19 of $50(38 \%)$ female patients with PHSV. This difference is not statistically significant $(\mathrm{p}>0.05)$.

Seasonal variation. The seasonal variation of prevalence of PHSV and RHSV was similar, being

Table 1 Association between epidemiological and clinical features of PHSV and incidence of RHSV

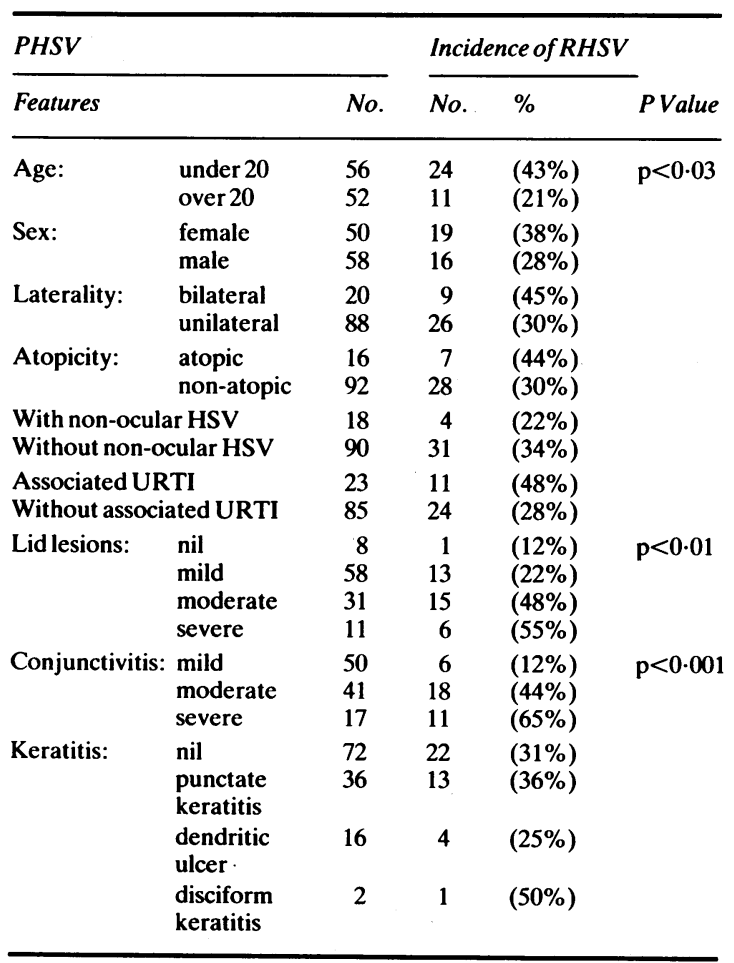

URTI= upper respiratory tract infection.

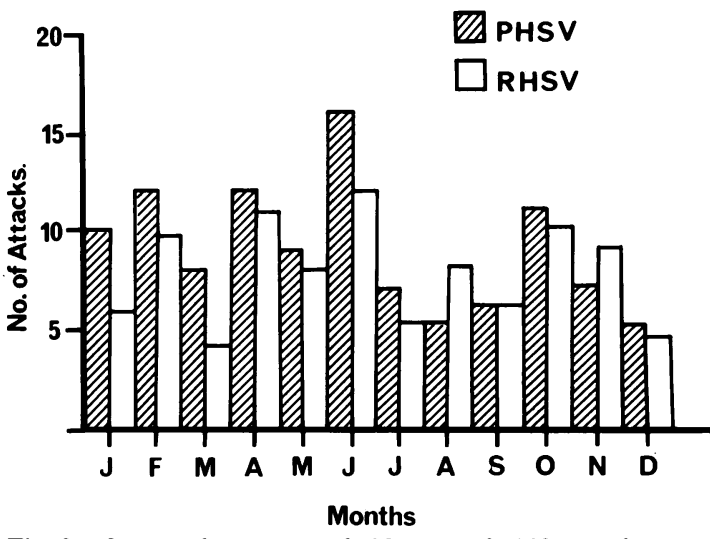

Fig. 2 Seasonal variation of 108 cases of PHSV ocular infection and the 93 subsequent attacks of RHSV ocular infections in 35 patients.

highest in June, but without any clear seasonal pattern during the rest of the year (Fig. 2).

Number of recurrences. Of 35 patients with RHSV ocular infection $17(49 \%)$ had one recurrent attack, $14(40 \%)$ two to five, and four ( $11 \%)$ six to 15 attacks. The total number of recurrences was 93 . In females RHSV attacks were evenly distributed in relation to age, but in males they were commoner in those under 15 years of age (Table 2 ).

Interval between attacks. The time interval between PHSV and the first RHSV ocular infection ranged from one month to four years, mean 10 months. The intervals between second, third, and fourth attacks were very similar, but in patients with more than four attacks the intervals were generally shorter, ranging from one to five months.

Duration and severity of attacks. The duration of each attack was usually shorter than the preceding one. PHSV ocular infection lasted 2.8 weeks on average, ${ }^{\prime}$ whereas the first recurrence lasted 1.8 weeks, the second 1.7 weeks, the third to sixth 1.4 weeks, and subsequent recurrences lasted for one week. The severity of disease was similarly reduced with successive recurrences.

PHSV severity and recurrence rate. Patients with more severe conjunctival signs during PHSV ocular infection had a higher incidence of recurrent infection than patients with less severe conjunctival signs (Table 1). This difference was statistically significant

Table 2 Number of recurrences in relation to sex and age

\begin{tabular}{lcl}
\hline & $\begin{array}{l}\text { Females } \\
\text { Patients/recurrences }\end{array}$ & $\begin{array}{l}\text { Males } \\
\text { Patients/recurrences }\end{array}$ \\
\hline Under 15 & $9 / 23$ & $7 / 26$ \\
15 and over & $10 / 28$ & $9 / 16$ \\
\hline
\end{tabular}


Table 3 Prevalence of symptoms in 35 patients during their first recurrent attack

\begin{tabular}{lcc}
\hline Symptoms & Number of patients & $\%$ \\
\hline Redness & 21 & 60 \\
Lid vesicles & 17 & 49 \\
Irritation and itching & 16 & 46 \\
Swelling of lids & 15 & 43 \\
Discharge & 14 & 40 \\
Watering & 9 & 26 \\
Photophobia & 7 & 20 \\
Blurred vision & 6 & 17 \\
Pain & 4 & 11 \\
\hline
\end{tabular}

$(p<0 \cdot 001)$. The severity of lid lesions was similarly related to a higher incidence of RHSV $(\mathrm{p}<0 \cdot 01)$. The recurrence rate also tended to be higher in patients with bilateral PHSV or with an associated upper respiratory tract infection, but it was not statistically significant $(p>0 \cdot 05)$. The severity of the corneal signs had no influence on the incidence of recurrent infection in contrast to lid and conjunctival signs.

Symptoms. The common symptoms during recurrences were mild to moderate redness, itching, irritation, lid swelling, and lid vesicles and/or ulcers. The frequency of symptoms during the first recurrent attack is shown in Table 3.

Signs. The major signs were associated with the lid, conjunctiva and cornea (Table 4).

Vesicles and/or ulcers of the eyelids occurred in 29 $(83 \%)$ patients. These were moderate in four $(11 \%)$ and mild in $25(71 \%)$. Six $(17 \%)$ patients had no lid lesions during the first RHSV ocular attack, but three of these developed lid lesions during second or subsequent recurrences. In eight $(23 \%)$ patients a chronic blepharitis consisting of mild to moderate lid margin erythema, swelling, scales, and meibomianitis developed in association with conjunctivitis. Only two of these eight patients had developed chronic blepharitis after their PHSV ocular infection.

The bulbar conjunctiva showed mild or moderate hyperaemia in $17(49 \%)$ and four $(11 \%)$ patients respectively. In the palpebral conjunctiva a papillary reaction was severe in one patient $(3 \%)$, moderate in $12(34 \%)$, and mild in $22(63 \%)$. In $14(40 \%)$ patients small and discrete follicles were found mainly in the lower lid conjunctiva.

Corneal signs were found during first or subsequent recurrences in $10(24 \%)$ patients. They included fine punctate keratitis in seven patients and dendritic ulcer in three. In one patient dendritic ulcer occurred during the first recurrence and in two patients during the second recurrence. In one patient dendritic ulcer was associated with disciform keratitis. In PHSV 16 $(15 \%)$ patients had dendritic ulcers.' Only five of
Table 4 Severity of signs during first recurrent attack

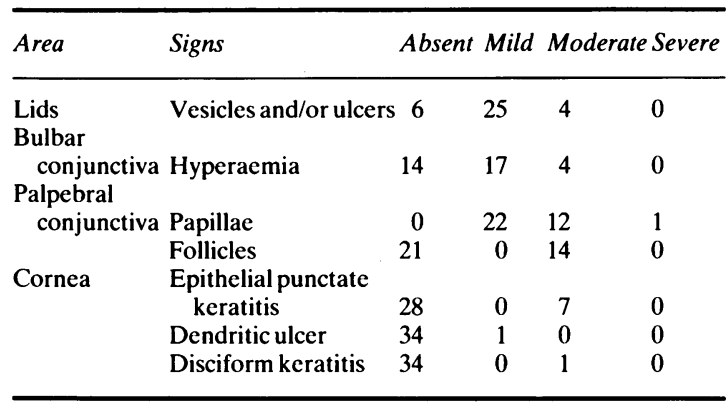

these $16(31 \%)$ developed a recurrent infection. Three of these who developed recurrences had normal corneas, one had only fine punctate epithelial keratitis, and one developed dendritic ulcer.

Virus isolation. Conjunctival specimens were collected from only 10 patients with RHSV, and virus was isolated from four of these.

\section{Discussion}

The results of the present study show several important epidemiological and clinical features of RHSV. The RHSV rate of $32 \%$ in our series is comparable with the rate of $40 \%$ reported earlier. ${ }^{5}$ In our patients the incidence of RHSV was significantly higher in males than in females and in males aged under 15. In the earlier studies it was found that RHSV was commoner in males aged 25 years and over than in males under 25 and in females. ${ }^{5.8}$ The cause of this increased susceptibility of males to recurrences is not known.

It is interesting to note that in our series the RHSV rate was closely associated with the overall severity of the PHSV, and in particular with the severity of the lids and conjunctival lesions. In contrast, however, there was no association between the severity of corneal disease and prevalence of RHSV. We have found that there are larger numbers of infectious virus particles in infected skin and conjunctiva compared with the cornea (unpublished observations). Hence it is possible that, when larger numbers of HSV particles are present, infection of the sensory ganglion may be facilitated, leading to a higher rate of recurrence.

The clinical presentation of RHSV in our group of patients is different from that in previous reports. It has generally been accepted that RHSV occurs mainly in the form of ulcerative keratitis, though occasionally it may present as conjunctivitis with or without lid lesions. ${ }^{x-10}$ In our series of patients with RHSV we found that corneal ulcers developed in only three of $35(9 \%)$ patients. In the remaining 
patients the disease presented as conjunctivitis with or without lid lesions and was slightly milder than the preceding episode. These findings indicate that corneal ulcer and stromal keratitis may occur in only a small proportion of patients with RHSV. In comparison, dendritic ulcer was detected in $16(15 \%)$ patients during PHSV.' Only five of these $16(31 \%)$ developed recurrent disease, and only two of these had corneal involvement during recurrent disease. These observations indicate that corneal involvement in PHSV does not necessarily carry a poor prognosis.

A chronic blepharitis was detected in eight $(23 \%)$ patients with RHSV. Of these, only two had similar problems during PHSV.' The development of a chronic blepharitis in association with PHSV or RHSV suggests that HSV is either the cause of chronic blepharitis or is a predisposing factor for the development of a secondary bacterial blepharitis.

The study was supported by a grant from the Department of Health and Social Security through Moorfields Eye Hosptial.

\section{References}

1 Darougar S, Wishart MS, Viswalingam ND. Epidemiological and clinical features of primary herpes simplex virus ocular infection. BrJ Ophthalmol 1985; 69: 2-6.
2 Darougar S, Viswalingam ND, Treharne JD, Kinnison JR, Jones BR. Treatment of TRIC infection of the eye with rifampicin or chloramphenicol. Br J Ophthalmol 1977; 61: 225-9.

3 Gordon FB, Harper JA, Quan AL, Treharne JD, Dwyer R St C, Garland JA. Detection of chlamydia (bedsonia) in certain infections of man. I. Laboratory procedures: comparison of yolk sac and cell culture for detection and isolation. J Infect Dis 1969; 120: 451-62.

4 McSwiggan DA, Darougar S, Rahman AFNS, Gibson JA. Comparison of the sensitivity of human embryo kidney cells, HeLa cells and W138 cells for the primary isolation of viruses from the eye. J Clin Pathol 1975; 28: 410-3.

5 Wilhelmus KR, Coster DJ, Donavan HC, Falcon MG, Jones BR. Prognostic indicators of herpetic keratitis. Arch Ophthalmol 1981; 99: 1578-82.

6 Thygeson P, Kimura SJ, Hogan MJ. Observations on herpetic keratitis and keratoconjunctivitis. Arch Ophthalmol 1956; 56: 375-88.

7 Leopold IH, Sery TW. Epidemiology of herpes simplex keratitis. Invest Ophthal Vis Sci 1963; 2: 498-503.

8 Laibson PR, Leopold IH. An evaluation of double-blind IDU therapy in 100 cases of herpetic keratitis. Ophthalmology 1964; 68: $22-34$.

9 Jones BR. The management of ocular herpes. Trans Ophthalmol Soc UK 1959; 79: 425-37.

10 O'Day DM, Jones BR. Herpes simplex keratitis. In: Duane TD, ed. Clinical ophthalmology. Hagerstown: Harper and Row, 1980:4:chapter 19:11-26.

Accepted for publication 16 September 1986. 